\title{
TELEHEALTH, SUSTAINABLE ECONOMIC DEVELOPMENT, AND SOCIAL WELFARE
}

\author{
Fuhmei Wang \\ Department of Economics, National Cheng Kung University, 1 University Road, Tainan 701, Taiwan \\ E-mail:fmwang@mail.ncku.edu.tw
}

Received 20 July 2011; accepted 09 October 2011

\begin{abstract}
Country experiences in Australia, New Zealand, Norway, Taiwan, and UK have been in favor of telehealth services since the early 1990s. Though a few studies do discuss evidence of the efficacy and cost-effectiveness of telehealth programs, the literature might limit to financial evaluation. This research investigates the welfare implications of conventional in-person and telecommunications health care as improving health levels or preventing health from deterioration for efficient resource allocation by incorporating government intervention for equal accessibility of health care in the economic progress perspective. Analytical findings indicate that the inverse $U$ shape relationship between telehealth expenditure share and social welfare status exists as the nonlinear nexus between telehealth expenditure share and economic growth presents. The health dividend in terms of an enhanced economic growth rate can be achieved only when the initial share of telehealth expenditure is smaller than the growth-maximizing share. For economic sustainable development, telehealth initiatives strengthen rather than compete with conventional in-person health care. Research results guide the countries, which have or will have telehealth systems, for effectively allocating medical resources to stimulate economic growth and improve the population's well-being.
\end{abstract}

Keywords: Telehealth, in-person health care, economic growth, welfare.

Reference to this paper should be made as follows: Wang, F. 2012. Telehealth, sustainable economic development, and social welfare, Technological and Economic Development of Economy 18(4): 711-721.

JEL Classification: I18, O11, O41.

\section{Introduction}

Equality of access of the population to health care services is an important political and public health issue for over three decades. The geographic, time, social and cultural barriers can prevent patients and providers to meet in person. Telecommunications systems offer new ways to practice medicine and are technologically based innovative systems for the remote 
delivery of personal health services, continuing medical education, and patient health education (Bashshur 1995). Country experiences in Australia, New Zealand, Norway, Taiwan, and UK have been in favor of telehealth services since the early 1990s by conducting a remote consultation with a general practitioner and guide him through a consultation with a patient by means of a two-way audio and video connection. The teleconsultation includes: teleradiology, teledermatology, telepathology, and telepsychiatry (Darkins, Cary 2000).

The World Health Organization (WHO) (Antezana 1997) distinguishes telemedicine from telehealth as the former incorporates these systems into curative medicine and is orientated more towards the clinical aspect and might be only associated with physicians while the latter covers health education, public and community health, health system development and epidemiology. For practical advantages, this research uses the term of telehealth rather than telemedicine to describe remotely delivered health services.

Decision makers and psychiatric consulters evaluate clinical applications of telehealth programs. Among evaluation studies, Roine et al. (2001) and Wade et al. (2010) provide systematic reviews of the literature. Two assessments contributed to the evaluation. One documents the effects of telecommunications systems on physician-patient communication and focuses on the accessibility of health care and perceptions of patients and clinicians (e.g. US Congress 1990; Puig-Junoy et al. 1998; Agha et al. 2009; Valls et al. 2010). Such evaluation might not analyze the variability of patient satisfaction with care. The other concentrates on the financial assessment of telehealth in rural health care networks and evaluates the financial consequences of decisions by comparing alternatives in financial terms (e.g. Bashshur 1995; Brent 2003; Dowie et al. 2008; Le Goff-Pronost, Sicotte 2010). The literature does discuss evidence of the efficacy and cost-effectiveness of telecommunications health services, albeit the criteria might limit to dollar value.

On the evaluation of conventional health care provision, equality of access is a standard for health services. Olsen and Rogers (1991) develop the welfare implications of health care by assuming a linear production possibility frontier and find that unequal access occurs in the absence of government intervention when agents care about equal access of goods. Based on normative economics, Hurley (1998) defines health care as encompassing those goods and services whose primary purpose is to improve or prevent deterioration in health. On the other hand, according to the US Department of Commerce (1999), information technology accounts for more than one third of the nation's real economic growth. A population with accessibility to online services, including health care, transportation, government and education, possesses better information about jobs, education, and health (Brodie et al. 2000; Autor 2001). Health care provisions through telecommunications are expected to link the economic growth and the development of new health services.

With this background, this research turns to provide a framework to investigate the welfare implications of conventional in-person and telecommunications health care as improving health levels or preventing health from deterioration for efficient resource allocation by incorporating government intervention for equal accessibility of health care in the economic progress perspective. Incorporating the contribution of Sen (1999) on welfare economics, economic growth should meet the demands of the people. This shows that a broader perspective of economic growth is required to take the most critical variables into account that are influenced by economic development. This research adheres to this principle and is based on 
the standard growth model of Barro (1990) to establish a new growth framework to analyze how the allocation of medical resources between telecommunications and in-person health care systems does affect economic progress and social welfare. This is one of the first papers to investigate the interrelationship between information technology, health care provision, economic growth, and well-being in the context of medical resource allocations.

In the following, Section 2 expresses agents and government's behavior. Section 3 provides numerical examples to estimate the optimal telehealth expenditure share for maximizing economic growth and social welfare. Section 4 discusses the policy implications and concludes.

\section{The analytical framework}

Consider an economy that is populated by households and firms. The representative household lives infinitely and pursues discounted lifetime utility maximization from consumption $C$, and from health, $H$.

$$
\int_{t=0}^{t=\infty}[\ln C(t)+\eta \ln H(t)] \exp (-\delta t) d t, \quad \eta>0,
$$

in which $\eta$ presents the positive impact of health on utility and $\delta$ is the time preference rate or subjective discount rate. In the following, time scripts have been dropped for simplicity. Individuals demand for health care services for improving levels of health and guarding against the effects of ill health. The provision of more health services through telecommunications $T$, and in-person $M$, health care systems leads to better health (Hurley 1998):

$$
H=\dot{T}+\dot{M} \text {. }
$$

On the production side, the household producer possesses the following production technology:

$$
y=A k^{\alpha} g^{1-\alpha},
$$

in which $A$ is the technological parameter, $\alpha$ and $1-\alpha$ respectively represent the elasticity of real output with respect to per capita capital stock, $k$, and government purchases of goods and services, $g$. All producers are symmetric, which implies that they set the same price and output in equilibrium. Goods market is perfect competition. The production function is concave with constant returns to scale and ensures that the maximization problem is well defined.

Government spends parts of output $\sigma y$, on health care expenditure, including spending on telecommunications health care $\beta \sigma y$, and in-person health care $(1-\beta) \sigma y$, as equations (4) and (5) present:

$$
\begin{gathered}
\dot{T}=\beta \sigma y, 0<\beta<1, \\
\dot{M}=(1-\beta) \sigma y, \\
\lim _{t \rightarrow \infty}\left(\frac{T}{M}\right)=\frac{\beta}{1-\beta} .
\end{gathered}
$$

Equation (6) has used the initial condition, $T_{0} / M_{0}=\beta / 1-\beta$, and the assumption that telecommunications and in-person health services are not reversible (Mankiw 1987; Zou 1995). Government establishes a national health insurance system to provide free accessibility to 
health care through conventional in-person system. Households pay proportional income tax, $\tau y$, and health insurance premium, $\phi(1-\beta) \sigma y$, in a national health insurance system to the government. Government also provides telehealth programs to people who have geographic and other difficulties accessing face-to-face health services. Telecommunications have considerable potential for improving health care provision for rural areas and under-served populations. The public-sector balanced budget constraint is:

$$
g+\dot{T}+\dot{M}+\frac{1-\beta}{\beta} \varepsilon y=\phi(1-\beta) \sigma y+\tau y .
$$

Government finances its infrastructure expenditure, $g$, an increase in telehealth spending, $\dot{T}$, an increase in conventional in-person health care spending, $\dot{M}$, and the expenditure on transportation costs through health insurance premium collection and revenue of income tax. Without telecommunications health care provision, patients or practitioners with weak confidence request air-transport transfers to medical centers for illness treatment inevitably in rural areas (Berman, Fenaughty 2005; Chen et al. 2001). The expenditure devoted to helicopters and fixed winged aircraft is substantial and proportional to national production, $\varepsilon y$. With telehealth programs, such expenditure is able to be reduced or saved. This expenditure decreases with the share of health expenditure devoted to telehealth and increases with the share of health expenditure devoted to in-person medicine and is captured by the fourth term on the left-hand side of equation (7). Rearranging government budget constraint (7), together with the production function (3), generates:

$$
\frac{g}{k}=\left[\phi(1-\beta) \sigma+\tau-\sigma-\frac{1-\beta}{\beta} \varepsilon\right]^{\frac{1}{\alpha}} A^{\frac{1}{\alpha}} .
$$

When goods market is in equilibrium, the budget constraint of government and the disposable income of the representative household have been incorporated. Equation (9) gives the capital accumulation function:

$$
\dot{k}=\left[1-\phi(1-\beta) \sigma-\tau+\sigma+\frac{1-\beta}{\beta} \varepsilon\right] y-C .
$$

Given the initial private capital $k_{0}$, the optimal conditions lead to the following relationships:

$$
\begin{gathered}
\frac{1}{C}=\frac{\eta}{H}=\lambda, \\
\frac{\dot{\lambda}}{\lambda}=\delta-\left[1-\tau-\phi(1-\beta) \sigma+\sigma+\frac{1-\beta}{\beta} \varepsilon\right] A \alpha k^{\alpha-1} g^{1-\alpha},
\end{gathered}
$$

where $\lambda$ is the costate variable which can be interpreted as the shadow value of the private capital stock measured in utility terms. Differentiating equation (10) with respect to time and substituting equation (8) into the resulting equation, equation (12) determines the growth rate of consumption, which is also the improvement rate of health and the growth rate of income, under our framework.

$$
\begin{gathered}
\frac{\dot{C}}{C}=\gamma=(1-\Omega) A^{\frac{1}{\alpha}} \alpha \Omega^{\frac{1-\alpha}{\alpha}}-\delta, \Omega=\phi(1-\beta) \sigma+\tau-\sigma-\frac{1-\beta}{\beta} \varepsilon, 1>\Omega>0, \\
\lim _{t \rightarrow \infty} \lambda(t) k(t)=0 .
\end{gathered}
$$


This growth rate depends on the gap between net marginal productivity of capital per capita and time preference rate. The telecommunications health care indirectly affects the growth rate via the ratio of telehealth expenditure share relative to in-person health care expenditure share. Equation (13) is the transversality condition, which restricts $k$ from growing too fast.

Maximizing equation (12) with respect to $\beta$ and taking into account the best medical resource allocations yields the following:

$$
\frac{\partial \gamma}{\partial \beta}=A^{\frac{1}{\alpha}} \alpha \Omega^{\frac{1-\alpha}{\alpha}}\left[1-\frac{1-\alpha}{\alpha} \Omega^{-1}(1-\Omega)\right]\left(\phi \sigma-\varepsilon \beta^{-2}\right) \stackrel{>}{<} .
$$

Equation (14) indicates that an increase in the share of telehealth expenditure has an ambiguous impact on the equilibrium growth rate. The key factors for this result are how the telecomunications and the in-person health care sectors interact with the ratio of health insurance premium relative to in-person health care expenditure, $\phi$, in the medical resource allocations and the elasticity of real output with respect to capital stock, $\alpha$. A rise in the share of telehealth expenditure, $\beta$, can affect economic performance through two channels. The first is the medical resources crowding out effect whereby an increase in telehealth expenditure reduces health expenditure on in-person health care. This channel tends to deteriorate agents' health status, as equation (2) shows, and hence the productivities in an economy. The second is the effects of health improvement whereby an increase in telehealth share tends to improve agents' health status. This channel has positive effects on private productivities and leads to better economic performance. The net effect of a rise in telehealth expenditure share on economic growth depends upon the relative strength of these two channels. Obviously, a rise in the share of telehealth expenditure favors (deters) the balanced growth rate if it improves (deteriorates) agents' heatlh status.

From equation (14), we can find a critical value of $\beta$, namely $\beta^{*}$, which maximizes the balanced growth rate:

$$
\beta^{*}=\left(\frac{\varepsilon}{\phi \alpha}\right)^{1 / 2}
$$

This implies that for attaining the maximization rate of economic growth, the optimal fraction of health care spending, allocated to telehealth programs, is the fraction of health care expenditure, devoted to the transportation costs, $\varepsilon$, to the product of the ratio of health insurance premium, relative to in-person health care expenditure, $\phi$, and the elasticity of output with respect to capital stock, $\alpha$. An economy that devotes more expenditure on air-transport transfers for illness treatment or collects less health insurance premium from private sector should have a bigger proportion of health care spending allocated to telehealth programs, as high quality in-person health care is difficult to access and medical resources are unequally distributed in rural areas. Furthermore, the smaller elasticity of real output with respect to capital stock, or the less the capital contributes to the production, the bigger the telehealth share in the economy should be in that the less the crowding out effects of telehealth expenditure on in-person health expenditure, which accumulates the agents' health stock and hence stimulates productivities.

By using equation (15), equation (14) can be rewritten as follows:

$$
\frac{\partial \gamma}{\partial \beta}=A^{\frac{1}{\alpha}} \alpha \Omega^{\frac{1-\alpha}{\alpha}}\left[1-\frac{1-\alpha}{\alpha} \Omega^{-1}(1-\Omega)\right]\left(\phi \sigma-\varepsilon \beta^{*-2}\right) \underset{<}{>} \text { if } \beta^{*}=\left(\frac{\varepsilon}{\phi \alpha}\right)^{1 / 2} .
$$


Equation (16) implies that the economy's balanced growth rate is raised by increasing the fraction of health care expenditure allocated to telehealth systems, if the actual fraction of telehealth spending is smaller than the growth-maximizing fraction of telehealth spending. Applying the information technology into health care provision is related to improving health stock and increasing national productivity. The positive relationship between health services, the health of a nation, and its economic prosperity is well recognized (Pritchett, Summers 2001; Olsen, Dahl 2007). When the economy introduces a telehealth system, the positive impacts arise through improving health and hence raising productive capacity. Nevertheless, after the critical ratio, the growth effects become negative as the telehealth system expands and in-person heath care system contracts. The net influence of telehealth resource use on economic growth reveals a non-linear and concave function, describing the relationship between the size of the telehealth provision and economic growth in the economy. The health dividend in terms of an enhanced economic growth rate can be achieved only when the initial share of telehealth expenditure is smaller than the growth-maximizing share.

We further analyze the influences of medical resource reallocation between telehealth and in-person health care expenditure on social welfare. This research regards social welfare as the overall welfare of society and is specified as the summation of the utils of all the individuals' utility function in the society (Chipman, Moore 1978). Given initial private capital stock $k_{0}$, both private consumption and health stock grow at a constant rate $\gamma^{*}$ along the balanced growth path:

$$
\begin{aligned}
& C_{t}=C_{0} \exp \left(\gamma^{*} t\right), \\
& H_{t}=H_{0} \exp \left(\gamma^{*} t\right) .
\end{aligned}
$$

For a given value of $\beta$, equations (17) and (18) have calculated the initial values of consumption and health stock from equations (2) and (9):

$$
\begin{gathered}
C_{0}=k_{0}\left[(1-\Omega) A\left(\frac{g}{k}\right)^{1-\alpha}-\gamma\right], \\
H_{0}=\sigma A k_{0}\left(\frac{g}{k}\right)^{1-\alpha} .
\end{gathered}
$$

Substituting equations (17) and (18) into equation (1) yields the household's welfare function of $\beta$ over an infinite planning horizon:

$$
\operatorname{Max} W(\beta)=\operatorname{Max} \int_{t=0}^{t=\infty}\left[\ln C_{0}+\eta \ln H_{0}+(1+\eta) \gamma^{*} t\right] \exp (-\delta t) d t .
$$

Substituting the initial values of $C_{0}$ and $H_{0}$ in equations (19) and (20) into equation (21) and differentiating the resulting equation with respect to $\beta$ yields:

$$
\frac{\partial W}{\partial \beta}=\frac{\omega}{\delta} \frac{\partial \gamma^{*}}{\partial \beta}=0,
$$

in which $\omega=\omega_{1} \alpha^{-2} k_{0} A(g / k)^{-\alpha}(1-\alpha)\left[(1-\Omega) \omega_{2} / C_{0}+\eta \sigma / H_{0}\right]-\left(k_{0} / C_{0}\right)+(1+\eta / \delta)$, $\omega_{1}=\left[-1+(1-\alpha) \Omega^{-1}(1-\Omega) / \alpha\right]^{-1}$ and $\omega_{2}=\left[1-A^{\alpha}(g / k)(\alpha / 1-\alpha)(1 / 1-\Omega) \Omega^{\alpha / 1-\alpha}\right]$ are positive. Equation (22) reveals that an increase in telehealth share affects social welfare via the channel of economic growth effects and the inverse $U$ shape relationship between telehealth expenditure share and social welfare status exists as the nonlinear nexus between telehealth 
expenditure share and economic growth presents. The relative size of telehealth expenditure that maximizes welfare equals the value that maximizes the growth rate (i.e., $\partial \gamma / \partial \beta=0$ applies). A bigger telehealth share is associated with better welfare status. However, after a critical telehealth share, the negative impacts on the population's health, the economy's growth and social welfare are expected. Figure 1 illustrates how telehealth use is theorized to influence the economic growth rate and social welfare.

During developing episodes, underdeveloped telecommunications infrastructure requires investing and capitalizing in online health care equipment and leads to an increases in the share of telehealth expenditure of medical spending. After the technical medical environment has profoundly transformed, only regular maintenance expenditure occurs and helps to reduce the telehealth expenditure share in a growing economy. Ultimately, for economic sustainable development, telehealth initiatives strengthen rather than compete with conventional in-person health care.

\section{Numerical simulations}

By applying the theoretical findings, this study further provides numerical simulations to present empirical plots of telehealth use versus economic growth and welfare status. Parameter values represent Taiwan experiences over the period of 1995-2004. All telehealth programs were grant-funded and either did not or could not sustain themselves commercially over the period. Health care provided via telecommunications has become of services for enhancing the handicapped or the terminally ill individuals' perceptions of their relationship to salient features of the environment in the private sector in Taiwan since 2004 because the cost-benefit analysis conducted by the government sector casts doubt on the efficiency of the telehealth system and guides medical resource allocation. Such provision is still in multidimensional concepts and qualitative pilot experiments. The productivity parameter, $A$ is chosen at 2.55 in consistence with the average real per capita economic growth rate of $4.5 \%$ from 1995 to 2004 in Taiwan from the reports of Council for Economic Planning and Development in 2004. Time preference rate of 0.02 is adapted from Jones and Manuelli (1995). The impact of health on utility is set at 0.48 , which is inspired by Finkelstein et al. (2010). The average rate of national health insurance premium in the private sector for in-person health care, $\phi$, in Taiwan in 2004 is 5 per cent. Average income tax rate is 15 per cent. The share of health expenditure to output, $\sigma$, is 10.1 per cent. The shares of telehealth and in-person health care expenditure of medical spending are 0.00006 and 0.99994 , respectively.

Based on the benchmark parameter values, equations (12), (15), and (19)-(21), and given the initial capital stock at 100, the equilibrium economic growth rate, the optimal growth maximization telehealth expenditure share, the initial values of consumption and health stock, the ratio of government expenditure relative to capital stock, and welfare in order are calibrated as: $\gamma^{*}=4.5 \%, \beta^{*}=0.022, C_{0}=15.10, H_{0}=2.24, \mathrm{~g} / \mathrm{k}=0.03$, and $W=57.87$.

Numerical simulations provide quantitative estimates of the impacts of medical resource allocations on the reported economic growth and welfare. The optimal telehealth expenditure share for maximizing economic growth and social welfare is 0.022 instead of 0.00006 that is actually allocated. According to Figure 1, economic growth and welfare will reach the 
maximization at 8.8 per cent and 114.12 when the telehealth expenditure share is allocated at the optimum instead of actual economic growth and welfare at 4.5 per cent and 57.87. Comparing to actual economic perspectives as well as welfare status, medical resource reallocation doubles the economic growth rate and social welfare. Taiwan's actual telehealth services are underprovided.

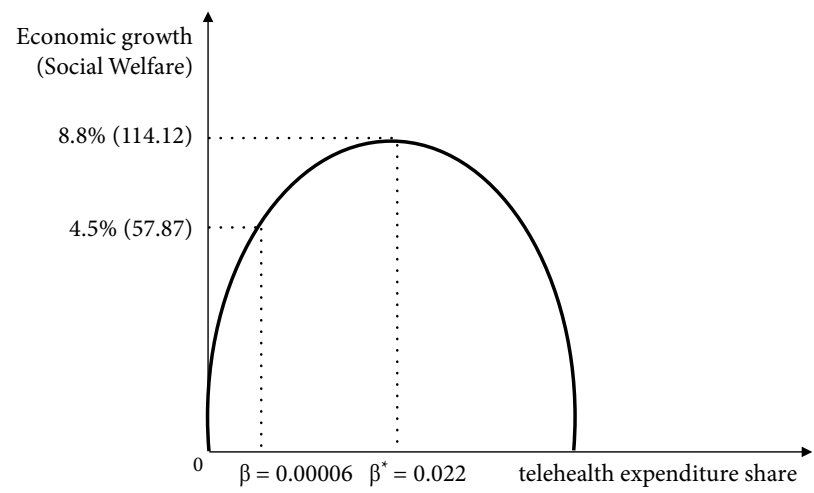

Fig. 1. The relationship between telehealth expenditure share and economic growth as well as welfare

\section{Discussions and policy implications}

In the light of the principal recommendations from preceding analysis, this section briefly reviews the influences of government interventions on medical resource allocation on the economy and the design of health care delivery programs in countries with geographic barrier and other difficulties for the population to access health services.

Over the coming 50 years, not only developing countries but also many industrialized countries will face sharp rises in the health expenditure and similar long-term health care challenges. Providing health services to promote better life for chronically ill patients is a recent phenomenon in most of these countries. Telehealth systems reduce access barriers by allowing patients and health care providers to meet remotely through the use of information technology. The provision of telecommunications health care transfers electronic medical data or consultation from one to another remote site simultaneously. Primary health care providers, medical centers, and community hospitals offer interactive communication among different specialties for illness treatment and improve the quality of health care in rural areas. In addition, health services via telecommunications system have been extended to provide palliative home care for terminal illness or telecare for the elderly and the disabled. A growing alignment of telehealth around the delivery of primary care and preventive health care services to people in their own homes is expected in the future.

Given health care spending, we should ask if health services through online technologies are having the desired impact on a nation's economic perspectives and welfare improvement. Theoretical analysis and numerical simulations suggest that with actual telehealth share, rais- 
ing medical resources allocated to telehealth programs effectively leads to the attainment of better economic performance and welfare position, which should be only accompanied with better health for the population (Pritchett, Summers 2001; Olsen, Dahl 2007). The provision of telehealth services interacts positively with socioeconomic perspectives before the critical or optimal ratios, which are actually unmet economic growth and social welfare goals. Research investigations guide the policy of allocating medical resources. Beyond financial evaluations, these findings are possibly much more important sources of economic development and welfare improvement and derived from policies aimed at promoting telehealth programs. Though in-person health services and hospitals are important for the delivery of health care and are likely to remain so in the future, telehealth offers ways of providing locally accessible services and new approaches to maintain a healthy lifestyle.

Telecommunications health services possibly possess externalities as conventional health services do, documented by Culyer and Simpson (1980). Market exchange yields less than socially optimal levels of such services. Existing studies focused on analyzing the cost and benefits of government interventions on the concept of public goods and externalities. This research provides a more paternalistic guidance of medical resource allocations.

Although our findings are specific to locations where geographical limitation may impede access to public sector health services for the rural residents, similar concerns for managing a telehealth care system are equally relevant for other countries to improve access to health care for people living far away from medical centers with and without a health insurance system. Potential replicability of relevant implication is applicable for other countries, which have or will have telehealth systems, for effectively allocating medical resources with sustainable economic development and improving population's well-being.

\section{Acknowledgement}

The author is thankful to the National Science Council in Taiwan for providing the foreign research scholarship, 99-2918-I-006-014 and to the Fulbright Foundation for the 2009-2010 research awards. Part of this research is conducted when the author was visiting as a scholar at the Department of Economics, Purdue University. The author thanks the hospitality offered by the Department, especially John Barron, the department chair. The author has no conflicts of interest relevant to the content of this study.

\section{References}

Antezana, F. 1997. Telehealth and Telemedicine will Henceforth be Part of the strategy for health for all [online]. Available from Internet: http://www.who.int/archives/int-pr-1997/en/pr97-98.html.

Agha, Z.; Roter, D. L.; Schapira, R. M. 2009. An evaluation of patient-physician communication style during telemedicine consultation, Journal of Medical Internet Research 11(1): 36-41. http://dx.doi.org/10.2196/jmir.1193

Autor, D. 2001. Wiring the labor market, Journal of Economic Perspectives 15(1): 25-40. http://dx.doi.org/10.1257/jep.15.1.25

Barro, R. 1990. Government spending in a simple model of endogenous growth, Journal of Political Economy 98(5): S103-S125. http://dx.doi.org/10.1086/261726 
Bashshur, R. L. 1995. On the definition and evaluation of telemedicine, Telemedicine Journal and e-Health 1(1): 19-30.

Berman, M.; Fenaughty, A. 2005. Technology and managed care: patient benefits of telemedicine in a rural health care network, Health Economics 14(6): 559-573. http://dx.doi.org/10.1002/hec.952

Brent, R. J. 2003. Cost-Benefit Analysis and Health Care Evaluations. Northampton, MA: Edward Elgar Publishing.

Brodie, M.; Flournoy, R. E.; Altman, D. E.; Blendon, R. J.; Benson, J. M.; Rosenbaum, M. D. 2000. Health information, the internet, and the digital divide, Health Affairs 19(6): 255-265.

http://dx.doi.org/10.1377/hlthaff.19.6.255

Chen, H. S.; Guo, F. R.; Chen, C. Y.; Chen, J. H.; Kuo, T. S. 2001. Review of telemedicine projects in Taiwan, International Journal of Medical Informatics 61(2-3): 117-129.

http://dx.doi.org/10.1016/S1386-5056(01)00134-4

Chipman, J. S.; Moore, J. C. 1978. The new welfare economics 1939-1974, International Economic Review 19(3): 547-584. http://dx.doi.org/10.2307/2526326

Culyer, A.; Simpson, H. 1980. Externality models and health: a Ruckblick over the last twenty years, Economic Record 56(154): 222-230. http://dx.doi.org/10.1111/j.1475-4932.1980.tb01672.x

Darkins, A. W.; Cary, M. A. 2000. Telemedicine and Telehealth: Principles, Policies, Performance, and Pitfalls. New York: Springer.

Dowie, R.; Mistry, H.; Young, T. A.; Franklin, R. C. G.; Gardiner, H. M. 2008. Cost implications of introducing a telecardiology service to support fetal ultrasound screening, Journal of Telemedicine and Telecare 14(8): 421-426. http://dx.doi.org/10.1258/jtt.2008.080401

Finkelstein, A.; Luttmer, E.; Notowidigdo, M. 2010. What good is wealth without health? The effect of health on the marginal utility of consumption. NBER Working Papers 14089.

Hurley, J. 1998. Welfarism, extra-welfarism, and evaluative economic analysis in the health sector, in Health, Health care and Health Economics, Perspectives on Distribution, Barer, M.; Getzen, T.; Stoddart, G. (Eds.). Toronto: John Wiley and Sons, 373-396.

Jones, L. E.; Manuelli, R. E. 1995. Growth and the effects of inflation, Journal of Economics Dynamic and Control 19(8): 1405-1428. http://dx.doi.org/10.1016/0165-1889(94)00835-6

Le Goff-Pronost, M.; Sicotte, C. 2010. The added value of thorough economic evaluation of telemedicine networks, European Journal of Health Economics 11(1): 45-55.

http://dx.doi.org/10.1007/s10198-009-0162-5

Mankiw, N. G. 1987. Government purchases and real interest rates, Journal of Political Economy 95(2): 407-419. http://dx.doi.org/10.1086/261462

Olsen, K. M.; Dahl, S. A. 2007. Health differences between European countries, Social Science and Medicine 64(8): 1665-1678. http://dx.doi.org/10.1016/j.socscimed.2006.11.031

Olsen, E. O.; Rogers, D. L. 1991. The welfare economics of equal access, Journal of Public Economics 45(1): 91-105. http://dx.doi.org/10.1016/0047-2727(91)90049-8

Pritchett, L. O.; Summers, L. H. 2001. Wealthier is healthier, Journal of Human Resources 31(4): 841-868. http://dx.doi.org/10.2307/146149

Puig-Junoy, J.; Saez, M.; Martinez, G. E. 1998. Why do patients prefer hospital emergency visits? A nested multinomial logit analysis for patient-initiated contacts, Health Care Management Science 1(1): 39-52. http://dx.doi.org/10.1023/A:1019082232606

Roine, R.; Ohinma, A.; Hailey, D. 2001. Assessing telemedicine: a systematic review of the literature, Canadian Medical Association Journal 165(6): 765-771.

Sen, A. 1999. Development as Freedom. Oxford: Oxford University Press. 
US Department of Commerce 1999. The Digital Work Force: Building Infotech Skills at the Speed of Innovation. Office of Technology Policy, Washington, D.C.

US Congress 1990. Office of Technology Assessment, Recombinant Erythropoietin: Payment Options for Medicare. Washington, D.C.

Valls, A.; Gibert, K.; Sanchez, D.; Batet, M. 2010. Using ontologies for structuring organizational knowledge in home care assistance, International Journal of Medical Informatics 79(5): 307-387. http://dx.doi.org/10.1016/j.ijmedinf.2010.01.012

Wade, V. A.; Karnon, J. A.; Elshaug, G.; Hiller, J. E. 2010. A systematic review of economic analyses of telehealth services using real time video communication, BMC Health Services Research 10: 233. http://dx.doi.org/10.1186/1472-6963-10-233

Zou, H. F. 1995. A dynamic model of capital and arms accumulation, Journal of Economic Dynamics and Control 19(1-2): 371-393. http://dx.doi.org/10.1016/0165-1889(93)00786-4

Fuhmei WANG. She received the Ph.D. degree in 1996 in Economics from Birmingham University, UK and is a professor at the Department of Economics, National Cheng Kung University, Taiwan since 2003. Her research interests include telemedicine, economic growth, and international economics and her work appeared in Journal of Economics, Journal of Telemedicine and e-Health, Emerging Markets, Finance, and Trade, and so on. She was awarded the 2009-2010 Fulbright research award as well as foreign research scholarship of National Science Council in Taiwan on the telehealth project. She is a Fulbright scholar at the Department of Economics of Purdue University. 